\title{
Lecture
}

\section{The Interplay of Mathematics and Finance}

\author{
AMBER HABIB \\ Department of Mathematics, Shiv Nadar University
}

(Delivered on 17 December 2019)

\begin{abstract}
Mathematics has been applied to problems involving loans and investments from very early times. The Mesopotamians were calculating compound interest around 2000 BC. Later, in India and China, problems of debt were used to motivate negative numbers. The connections have only strengthened with time and the flow of ideas has been especially rich in the last century. We give a brief history of these connections and also explore the role of finance in the teaching of mathematics and as a career for mathematicians.
\end{abstract}

\section{Introduction}

All mathematical development has its psychological roots in more or less practical requirements. But once started under the pressure of necessary applications, it inevitably gains momentum in itself and transcends the confines of immediate utility.

-Courant \& Robbins, 1941.

Elements of mathematical thinking are found from the very dawn of civilization, with counting sticks and geometric cave art dated to about 20,000 years ago. We can only speculate about their precise significance for our ancestors, but the attraction towards abstract patterns is evident. Important markers of the progress of humankind have been accompanied or facilitated by developments in mathematics. This includes the use of mathematics in financial accounting and planning, in assessing and compensating for risk, and in expanding our notions of what kinds of objects can be traded and at what value. Financial institutions provide means of satisfying investors' requirements by matching their needs with each other. This is done through devices like loans and interest, bonds, insurance, shares, and advanced contracts called financial derivatives. The mathematical treatment of issues related to these involves diverse areas of modern mathematics, such as:
- Probability and Statistics

- Optimization

- Numerical Methods

- (Partial and Stochastic) Differential Equations

- Measure Theory and Functional Analysis

The presence of the first two or three topics in this list should not surprise anyone. The last two are an indicator of a certain level of axiomatisation of finance, with the presence of fundamental principles that lend themselves to the formulation of differential equations. They are also more advanced, usually taught at graduate level, and show that finance offers intellectual challenges for the mathematician.

The relationship between mathematics and finance has featured prominently in the news during the past few years. Here is a headline:

\section{Math Nerds are Taking Over Wall Street -CNN Business, July 14, 2014.}

Articles like these describe how modern mathematics is being applied by investment banks and other financial institutions. The 'math nerds' of the title could be mathematicians, as well as physicists and computer scientists. They would have studied these subjects at least till the masters level, and may even have doctorates in them. Finance offers them

*Authorfor Correspondence: E-mail: amber.habib@snu.edu.in

${ }^{\#}$ Lecture delivered in the Mathematics and Society Symposia during the INSA Anniversary General Meeting, 2019 at CSIR-NIO, Goa 
an exciting and remunerative career track. At the same time, there is a fear that the new strategies based on technical advances in mathematics and computing are more opaque to human understanding, so that it becomes harder to judge just how badly things can go, when they go badly. Thus, we also have headlines like the following:

\section{How Mathematics May Have Caused the Financial Crisis}

-CBS News, April 15, 2010.

We begin this essay with a few episodes from history to illustrate how the two subjects have been intertwined from their beginnings. Then we look at the rapid developments over the past century, and consider how finance has acquired some basic principles on which the mathematical work can be based. We close with a discussion of how topics from finance can be connected with or included in the university mathematics curriculum.

\section{History}

In this section, we give a few examples of how financial problems and mathematical developments have gone hand-in-hand through the ages.

Among the ancient civilizations, we know the most about the commercial and scientific practices of the Mesopotamians, simply because they etched their records on clay tablets, and these have survived in large numbers. Some tablets contain contracts, others carry practice problems, sometimes with solutions. For example, a tablet which is now in the Louvre and is dated to about $2000 \mathrm{BC}$, asked "How many years will it take for a loan to double?" The subsequent calculations show that the interest was compounded annually at $20 \%$. After 3 years it becomes $(6 / 5)^{3}=1 \frac{91}{125}$ of the original and after 4 years it becomes $2 \frac{45}{625}$. This establishes that the answer is between 3 and 4 years. To find the exact answer, the scribe let the interest accumulate linearly during the fourth year, just as we might today, leading to the solution $3+\frac{47}{60}+\frac{13}{60^{2}}+\frac{20}{60^{2}}$ years (Curtis, 1978).

In India, Kautilya's Arthashastra described desirable accounting practices, mentioning types of income, classification of expenditures, and the notions of assets, debts and capital. It has been suggested that these book-keeping practices were among the factors that facilitated Indian creation and acceptance of the zero and of negative numbers (Mattessich, 1998). Certainly, when negative numbers were presented by Brahmagupta in the 7th century AD, the concept of debt was built into the very terminology. He used the Sanskrit word for wealth or fortune to denote positive numbers and the word for debt or loss to denote negative numbers.

It is well-known that the Indian numerals and the decimal place-value system, made their way via the Arabs to Europe. Among the Arabs, Al Khwarizmi treated problems of inheritance in the 9th century. Leonardo of Pisa, or Fibonacci, wrote a book Liber Abaci in 1202, in which he described the Indian numerals (including zero) and associated algorithms for arithmetic. While this book is now referred to mostly for the Fibonacci sequence, its actual thrust was commercial mathematics. Fibonacci applied the algebraic methods of Al Khwarizmi to problems of commerce and developed "a wide range of practical mathematical tools for calculating present value, compounding interest, evaluating geometric series, dividing profits from business ventures, and pricing goods and monies involving a complex variety [of] weights, measures and currencies" (Goetzmann, 2004).

The birth of Probability with the correspondence between Blaise Pascal and Pierre Fermat in 1654 was motivated by problems arising out of gambling. Gambling raises some of the same issues as finance. Consider the 'Problem of Points', which can be stated as follows: "Two individuals have staked a given amount to be paid to the one who is the first to win $n$ points. A point is awarded in a fair round in which each player has an equal chance of winning. If they decide to stop playing after the first player A has won $x<n$ points and the second player B has won $y<n$ points, what is a fair division of the stakes?" Pascal and Fermat created the notion of 'expectation' to resolve this problem, and valuing a random income by its expected value is now a fundamental idea in finance (though, in general, the expectation needs to be modulated by the associated risk to arrive at the correct value).

The concept of expected value arose separately as well, a little later, in the treatment of life annuities. These are annual payments of a constant amount that 
are made till the death of the purchaser of the contract. The value at the time of the purchase should depend on how long the purchaser expects to live. This analysis was carried out by de Witt in Holland in 1671, based on a mortality table that estimated how many people who have survived to a certain age would also survive to a given subsequent age (Rubinstein, 2006). Here we see one of the early applications of probability to statistics.

Risk entered the picture with a work of Daniel Bernoulli in 1738. He proposed that the presence of risk lowers the worth of a gamble. A gamble may achieve a large expected value by offering a huge payoff but at low probability. An investor would be put off by the low probability of success and would not be willing to pay the expected value. Bernoulli accounted for this risk aversion by introducing a concept of 'moral expectation' (now called 'expected utility') wherein an investor values a payoff by its logarithm, rather than by its actual value.

Thus, by the 19th century, several basic techniques and principles of finance had been identified. Nevertheless, their scope was quite limited. There was no modeling of fluctuations of prices or interest rates, no analysis of the dependence between different assets, and a limited understanding of risk.

\section{Modern Finance and Finance}

The modern mathematical approach to Finance begins with Louis Bachelier's PhD thesis Theory of Speculation, supervised by Henri Poincare, in Paris, 1990 (Bachelier, 1900). Bachelier was the first to consider how the price of an asset like a bond fluctuates with time. He viewed price fluctuations as due to a multitude of influences. This led him to model them, via the Central Limit Theorem, as given by the normal distribution. Thus he discovered what mathematicians now call additive Brownian motion. It has been remarked that his derivation of Brownian motion for the trajectories of prices parallels that of Einstein's (six years later) for the movement of suspended particles. Bachelier applied his insights to estimate prices for various contracts that were being traded on the Paris Stock Exchange, such as bond options. We give below a few of Bachelier's principles that have been foundational for later work:

1 At a given instant, the market does not believe in either a price rise or fall, since there as many buyers as sellers.

2 The expected profit for any speculator is zero, and this is true even for trades based on future price movements.

3 Probabilities of prices 'diffuse' over time according to the same law as followed by heat.

4 It is possible to conceive combinations of contracts that would yield profits under all circumstances, but these are never found in practice.

The last of these is a throwaway comment made while illustrating the working of different contracts and their combinations. Subsequently, others made it an axiom - the No Arbitrage Principle - and it became the standard starting point for pricing formulas.

Bachelier's thesis and subsequent work on Brownian motion did influence mathematicians such as Kolmogorov in formulating the general theory of stochastic processes. However, economists did not notice his work until the nineteen fifties. When they did, it led to a flurry of work applying stochastic calculus to finance. The climax was the BlackScholes-Merton approach to pricing options, published in 1973. The 'Black-Scholes formula' facilitated a boom in the use of financial derivatives - contracts that feature an exchange in the future and whose pricing therefore involves the modeling of price trajectories.

Starting with Bachelier's work, the normal distribution has been central to financial models. Assuming that price fluctuations are normally distributed amounts to saying that extreme events should be very rare. Is this really so? Even Bachelier developed doubts on this front later in life. By now, it is well-established that stock prices seem to be wilder than the normal distribution allows. Benoit Mandelbrot has given the following examples (Mandelbrot, 2005).

- $\quad$ According to theory, there should have been 58 days during 1916 to 2003 when the Dow Jones index moved by more than $3.4 \%$. There were 1,001 .

- An index swing of more than 7\% should happen once in 300,000 years. It happened on 48 days in one century! 
If the financial models underestimate extreme events, institutions will be vulnerable to them. The primary cautionary tale is that of Long-Term Capital Management, a hedge fund that aimed to detect and exploit arbitrage opportunities. LTCM was founded with the active participation of Robert Merton and Myron Scholes, who had won the Nobel Prize for their options pricing model. LTCM generated returns of $21 \%, 43 \%$ and $41 \%$ in its first three years, but then its performance tapered off as its methods were copied by others. It was finally wiped out by the 1997 Asian Financial Crisis and the 1998 Russian Financial Crisis. The global financial crisis of 2007 is also partially attributed to the use of models which relied on the normal distribution.

So why use the normal distribution? The answer seems to be, "Because we can". The empirical evidence is that heavy tailed stable distributions are a better fit to reality. But these are difficult to work with. One can do numerical fits to data, but there has been little progress in generating theoretical insights from them. For example, the two parameters of a normal distribution have easy interpretations as expected profit and risk when applied to prices. The parameters of stable distributions lack such interpretations.

Another issue is in exploring the influences of different assets on each other. This study too was properly launched in the nineteen fifties, with the $\mathrm{PhD}$ thesis of Harry Markowitz. He showed how quadratic programming could be used to seek a level of profit at minimum risk, provided that profit is measured by expected return and risk is measured by standard deviation. Most modern methods of portfolio design ultimately draw their inspiration from Markowitz, and hence do not use empirically justified models of price fluctuation. For the heavy tailed distributions have undefined expectation and standard deviation, and cannot be used in the Markowitz approach.

\section{References}

Bachelier Louis (1900) Théorie de la spéculation. Annales Scientifiques de l'Ècole Normale Supérieure $3^{\mathrm{e}}$ série, 17 21-86
Thus the world of speculative finance is riven by contradictions today. On the one hand, it relies heavily on advanced mathematics and complex mathematical models. These are combined with computing power for instant analysis and action. Yet these models are known to rest on assumptions which underestimate the danger of large shocks and every once in a while contribute to a collapse or a crisis. The resolution of these contradictions offers a fascinating challenge.

Finance offers a new solution to the problem of making mathematics education more interesting via applications of mathematics. It is possible even at the undergraduate level to give a reasonably complete treatment of the fundamental principles and their applications to portfolio design, financial derivatives, and hedging and investment strategies. The prerequisites are only calculus and basic probability (normal distribution, expectation and variance, covariance). Many text books are available, of different flavours. For example, [Capinski \& Zastawniak, 2003] and [Ross, 1999] are aimed at mathematics students and develop the theory in detail. My own text [Habib, 2011] seeks to pay more attention to using data to test or support the theory. In fact, spread sheet based computer labs bring the subject to life for the student and allow for an experimental and open-ended approach. Students aiming for careers like investment bankers and fund managers should aim for a Masters degree with a solid component of applied topics. Many quantitative analysts or 'quants' have first acquired a PhD in the mathematical sciences before making the switch. Greater awareness of these possibilities, among both students and faculty, may make for asignificant increase in the relevance of mathematics degrees for students' career paths.

Capiski Marek and Zastawniak Tomasz (2003) Mathematics for Finance: An Introduction to Financial Engineering. Springer Undergraduate Mathematics Series. London: SpringerVerlag 
Courant Richard and Robbins Herbert (2941) What is Mathematics? An Elementary Approach to Ideas and Methods. London: Oxford University Press

Curtis Lorenzo J (1978) Concept of the exponential law prior to 1900 American Journal of Physics 46 896-906

Goetzmann William N (2004) Fibonacci and the Financial Revolution, NBER Working Paper Series, Working Paper 10352, http: //www.nber.org/papers/w10352; 2004

Habib Amber (2011) The Calculus of Finance. Hyderabad: Univer- sities Press

Mandelbrot Benoit and Hudson Richard L (2005) The Misbehaviour of Markets: A Fractal View of Risk, Ruin and Reward. London: Profile Books
Mattessich Richard (1998) From Accounting to Negative Numbers: A Signal Contribution of Medieval India to Mathematics The Accounting Historians Journal 25 129145

Ross Sheldon M (1999) An Introduction to Mathematical Finance: Options and Other Topics. Cambridge: Cambridge University Press

Rubinstein Mark (2006) A History of the Theory of Investments. New Jersey: John Wiley \& Sons

Taqqu Murad S (2002) Bachelier and his Times: A Conversation with Bernard Bru. In H. Geman, D. Madan, S. R. Pliska and T. Vorst, editors, Mathematical Finance - Bachelier Congress 2000. Springer-Verlag. 